\title{
Tráfico humano E desarRanjos na PROTEÇÃo dos direitos humanos: CONFUSÕES CONCEITUAIS ENTRE TRÁFICO DE PESSOAS E CONTRABANDO DE PESSOAS
}

Human trafficking and breakdowns in the protection of human rights: conceptual confusions between trafficking in persons and smuggling of persons

\section{Waldimeiry Corrêa da Silva}

Doutora em Direito Internacional Público e Relações Internacionais pela Universidade de Sevilla. Professora do Programa de pós-graduação em Direito (Mestrado em Direitos Humanos) da Universidade Tiradentes/SE. E-mail: m_sevilla7@yahoo.es.

RECEBIDO EM: 25.02.2013

APROVADO EM: 14.06.2013

\section{Resumo}

No presente artigo buscamos realizar uma análise dos Direitos Humanos relacionados ao Tráfico de humano através dos conceitos do Tráfico de Pessoas (TP), e do contrabando de imigrantes. Objetivamos examinar as confusões conceituais dentro dos fluxos migratórios e as tensões para os direitos humanos derivadas da falta de clareza conceitual entre o TP e o contrabando de imigrantes. De um lado temos uma violação massiva de Direitos Humanos - que ocorre no processo do TP inseridos nos processos migratórios-. De outro, uma infração administrativa contra o Estado que ocorre no contrabando de imigrantes. Aproveitado do "vazio" deixado pela globalização, o crime transnacional organizado busca sacar benefícios financeiros das correntes migratórias, de modo que ocorre uma violação sistemática dos direitos humanos das vítimas do Tráfico de seres humanos.

Palavras-chave: Direitos humanos. Tráfico de seres humanos. Contrabando de IMIGRANTES. 


\begin{abstract}
In the present article, we analyze Human Rights though concepts such as Women Trafficking and Traffic with Immigrants - irregular smuggling with immigrants. Our objective is to examine the confusion in terminology present in migratory waves as well as tensions that arise from this lack of jargon clarity that often mistakes Women Trafficking for Irregular Traffic with Migrants. On the one hand, with Women Trafficking occurs a massive violation of Human Rights - that often takes advantage of migratory processes. On the other hand, human trafficking results in an administrative infringement against the State. As a result of the legal void left by globalization, the transnational organized crime aims at profiting as much as possible from waves of migration. Therefore, there is a systematic violation of the rights of victims of Women trafficking.
\end{abstract}

Key Words: Human Rights. Human trafficking. Traffic With immigrants.

SumÁRIo: Introdução. 1.Necessidade de uma clareza conceitual para a salvaguarda dos direitos humanos nos fluxos migratórios. 2. Tráfico de pessoas: primazia pelos direitos humanos? 3. Contrabando de imigrantes: infração administrativa e abuso da vulnerabilidade. 4 . Confusões conceituais entre o tráfico de pessoas e o contrabando ilegal de imigrantes. Conclusão. Referências.

\title{
INTRODUÇão
}

Foi somente a partir dos anos 1990 que a ligação entre o tráfico de pessoas (TP) e o contrabando de imigrantes ${ }^{146}$, também conhecido como imigração irregular, foi percebida. A partir de então, o Tráfico deixa de ser discutido no âmbito de outras questões relacionadas a direitos humanos, como a prostituição e a imigração ilegal de pessoas, e passa a ser o tema central de reuniões, produções doutrinárias e literárias bem como de, e políticas públicas. Nesse sentido, o relatório apresentado pela Secretaria de Estado dos EUA de 2010 adverte que: o TP é um movimento fluido que responde ás demandas do mercado, ao enfraquecimento das leis e das penalidades e à disparidade econômica fruto do mundo capitalista.

Com vistas a alcançar uma discussão conceitual que permita aliviar as ten-

${ }^{146}$ Neste contexto optamos pela tradução literal do término utilizado pela Convenção de Palermo: Smuggling como o Contrabando de imigrantes, de modo a enfatizar o ato delitivo como meio de entrada no território, de modo a que seja perceptível a fragilidade do sujeito (migrante) no processo migratório. 
sões de direitos humanos tangentes ao TP, optamos por uma divisão em três partes para realizar o presente estudo. Primeiramente este artigo apresenta o que consideramos "tensões e direitos humanos no Tráfico humano", a partir dos conceitos de Tráfico de seres humanos e Contrabando de imigrantes (ou imigração irregular). Buscando com isso trazer a necessidade de clareza conceitual para a promoção e proteção dos direitos humanos dos migrantes. Apresentaremos uma análise de como o Tráfico esta relacionado com as migrações internacionais e o crime transnacional organizado. Num segundo momento realizamos a comparação entre os elementos constitutivos de cada um dos conceitos de modo a comprovar que estamos diante instituições distintas desde o direito internacional, e que ao não levar em consideração tal fato gera uma violação de direitos humanos às vitimas TP. Posteriormente a definição de conceitos e análises de seu contexto dentro dos fluxos migratórios colocaremos em evidencia um quadro explicativo no qual buscamos evidenciar as diferencias conceituais entre TP e Imigração irregular. Concluiremos o presente estudo evidenciando as consequências de simplificar o debate sobre o tema para a vulneração de direitos.

Usamos metodologicamente o enfoque dos Direitos Humanos para determinar os conceitos estabelecidos pelos normativos internacionais para o TP, sua relação como uma forma contemporânea de escravidão e consequente violação de direitos humanos. Neste sentido, recorremos a uma análise descritiva e comparada para estudar os normativos internacionais e outros instrumentos internacionais. Vale enfatizar que temos em consideração a perspectiva de gênero no presente artigo, contemplando as variáveis de gênero e TP e os estereótipos de gêneros (papéis atribuídos a homens e a mulheres por razoes sócio-culturais) que são favorecedores da desigualdade, da dominação patriarcal e favorece tráfico de mulheres e a exploração do trabalho (seja laboral ou sexual). Para o presente entendemos que ao abordar a migração devemos trazer o ser humano ao centro do debate e para tanto tomamos a pertinente consideração realizada por HAZEU de que:

A migração não pode ser descrita como um processo linear, de um lugar (origem) para outro (destino), mas como processo que assume configurações complexas de cadeias, processos circulares, vivencias paralelas em vários lugares alternados, sem destinos definitivos (o lugar de origem pode se tornar um lugar de destino e o que foi destino se tornar origem) (2001, pp.16-17).

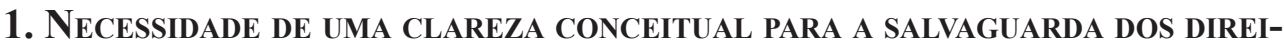 TOS HUMANOS NOS FLUXOS MIGRATÓRIOS}

O movimento transnacional de pessoas sempre esteve na pauta da agenda internacional, ora por sua preocupação em salvaguardar os direitos humanos das pessoas envolvidas no fluxo migratório, ora por políticas de imigração específicas 
que no admitem a entrada em algumas pessoas de determinadas nacionalidades em seu território sem previa autorização (vistos). Favorecendo com essa atitude um contexto de alto risco de desrespeito aos direitos humanos (GALLANGER, 2001, p. 25). Diante de semelhante afirmação se pode observar que os temas de Tráfico de seres humanos e contrabando de imigrantes não são preocupações do século XXI e, tampouco surgem do nada para tornam-se prioridades na agenda internacional por uma série de razões. Entre elas, a preocupação pelo ser humano, toda vez que estamos diante um fenômeno que comporta o deslocamento humano, que na maioria dos casos conflui em violação dos direitos humanos das pessoas vítimas de TP. A este respeito Vaz Cabral alega que ainda que a definição teórica entre TP e Contrabando de imigrantes seja clara teoricamente, na prática não é, já que ambas as práticas utilizam as mesmas rotas de imigração, em muitos casos as mesmas redes o que dificulta a visibilidade e a categorização de muitos fatos que se tornam complexos. Dai a importância de uma legislação que tenha uma definição clara com o fim de separar o que signifique ordem pública do que constitua uma violação de direitos humanos ${ }^{147}$. Nos últimos anos muito da mencionada preocupação da comunidade internacional relativa ao movimento migratório se dá principalmente pela penetração do crime transnacional organizado e dos controles fronteiriços. Já que aquele tem aproveitado a porosidade das fronteiras, tirado vantagem das inovações tecnológicas (Dentro desta trama a tecnologia tem um papel essencial no intercambio financeiro e no fluxo de informações já que diminui virtualmente o espaço mundial, possibilitando um contato mais complexo entre os seres humanos), bem como das lacunas existentes entre a diversidade dos sistemas jurídicos e suas instituições jurídicas ${ }^{148}$.

Dentro desta lógica está um grupo significativo de pessoas que poderiam ser beneficiados da permeabilidade das fronteiras devido à globalização, mas que do contrário situam-se a margem desta possibilidade tendo que recorrer a meios escusos para migrar. Neste sentido Cepeda assevera que as pessoas - ou trabalhadores não possuem ao mesmo grau de liberdade que o capital, do contrário, prevalece "dinâmica a la inversa a través de la multiplicación de barreras a su libre circulación.

${ }^{147}$ Em palavras de Vaz Cabral: "L'utilisation des mêmes trajectoires est moins évidente qu'en théorie. L'utilisation des mêmes trajectoires d'immigration, des mêmes réseaux et le constant va-et-vient entre les deux catégories rendent la visibilité des phénomènes et la qualification juridique des faits extrêmement complexes. C'est pourquoi il lest important que les législations nationales disposent d'une définition claire de la traite, de manière à dissocier ce qui relève $\mathrm{du}<$ trouble à ordre public $>$ et d'un $<$ crime contre la personne $>$." Em: VAZ CABRAL, G.: La traite des êtres humains. Realités de l'esclavage contemporain. Paris: La Decouverte, 2006, p.17.

${ }^{148}$ Neste sentido Calvani argumento que os grupos delitivos internacionais aproveitam da tríade: violência, corrupção e obstrução da justiça. Veja: CALVANI, S. Representante do UNODC, Bogotá-Colômbia, realiza um comentário pormenorizado sobre a Convenção de Palermo. Disponível em: http://www.sandrocalvani.com/speech/Conv.\%20Palermo.pdf Acessado em:24.05.2011. 
Los gobiernos han perdido el control sobre el capital, pero controlan férreamente las fronteras de los trabajadores." (CEPEDA, 2004, p.4). A migração irregular passa a ser vista como meio de alcançar melhores condições de vida, através de possibilidades alentadoras de trabalho. Como adverte Cançado Trindade recorrem ao subterfúgio da migração ilegal, como meio de escapar de situações de vulnerabilidade ás quais se encontramos, como fome, miséria, conflitos armados, etc. (CANÇADO TRINDADE, 2008, p.137).

Precisamente com vistas a paliar este vazio de poder que propicia a subsistência e/ou a penetração da delinquência organizada, que quebranta tanto leis administrativas do Estado, como os Direitos humanos de milhares de pessoas envolvidas nas correntes migratórias foi, elaborada a Convenção das Nações Unidas contra o Crime Organizado Transnacional ${ }^{149}$ - Convenção de Palermo - que foi suplementada por três protocolos adicionais, entre eles um referentes ao Tráfico de seres humanos O Protocolo Adicional à Convenção das Nações Unidas contra o Crime Organizado Transnacional Relativo à Prevenção, Repressão e Punição do Tráfico de Pessoas, em Especial Mulheres e Crianças ${ }^{150}$, também conhecido como Protocolo de Palermo -; e outro referente ao Contrabando de imigrantes - o Protocolo Adicional relativo ao Combate ao Tráfico de Migrantes por Via Terrestre, Marítima e Aérea ${ }^{151}$.

Os Estados que o assinaram e ratificam se colocam de acordo em que o TP consiste em um grave problema internacional e não é o mesmo que introduzir imigrantes ilegalmente ${ }^{152}$. A partir dos dois Protocolos mencionados, foram definidos os conceitos de trafficking e smuggling. De um lado, trafficking é definido como Tráfico de pessoas com fines de exploração, já seja para fins sexuais, laborais, remoção de órgãos, para fins de mendicidade ou adoção ilegal. De outro, smuggling se define com o contrabando irregular de pessoas.

O TP está inserido dentro dos fluxos migratórios e em sinergia com o Contrabando de imigrantes. Neste sentido não podemos deixar passar desapercebido o fato de que a migração internacional é também parte da historia da humanidade e como tem avançado junto a mesma ${ }^{153}$. Depois da destruição causada pela II Guerra

\footnotetext{
${ }_{149}$ Adotada pela Assembléia Geral da ONU no dia 15 de novembro de 2000, mediante a Resolução: $\mathrm{A} / \mathrm{RES} / 55 / 25$. Foi suplementada por três protocolos facultativos.

${ }^{150}$ Promulgado no Brasil mediante o Decreto N. 5.017 de 12 de março de 2004.

${ }^{151}$ Promulgado no Brasil pelo Decreto No 5.016, de 12 de março de 2004.

${ }^{152}$ Tal como podemos observar no Artigo 3 do Protocolo de Palermo. Para Gallangher, entre los fatores que distinguen estes dois atos juridicos, está "The profit in trafficking comes not form the movement but from the sale of a trafficked person's sexual services or labor in the country of destination." Veja também: GALLAGHER, A.: Trafficking, Smuggling and Human Rights, FM Review, Dic, 2001, p. 25.

${ }^{153}$ Neste sentido Del Rio Fernandez analisa como o movimento migratório mais importante que se deu com o descobrimento da America em 1942. E que a partir de então, se estima que, nos séculos XVI e XVII, entre 2 a 3 milhoes de europeus migraram para "o novo continen-
} 
Mundial, durante os anos 50 e 60, os países devastados pelas guerras se encontravam carentes de mão de obra, fato que veio a contribuir para que os fluxos migratórios transpassassem com maior facilidade. Não obstante, com a crise do Petróleo de 1973 gera uma mudança brusca em mencionada política migratória ${ }^{154}$, já que os países que anteriormente haviam fomentado as correntes migratórias - para suprir sua falta de mão de obra - começaram a dificultá-los, salvo algumas exceções firmadas mediante compromissos internacionais, como as obrigações de: reagrupação familiar, o direito de asilo e refugio, causas humanitárias, entre outras. Neste contexto surge então o termo: "imigração ilegal" - que até 1964 não existia e tinha um conceito distinto do que nos proporciona o Protocolo sobre o Tráfico irregular de imigrantes - para fazer referencia a "oleada" de imigração produzida pela chegada de imigrantes provenientes de países "menos desenvolvidos" ou "subdesenvolvidos" nos países "desenvolvidos" (ou do "primeiro mundo") em busca de melhores condições de vida. Deste modo, os países "desenvolvidos" estabelecem políticas de restrição à imigração dificultado e reduzindo às possibilidades de entrada legal em seus territórios nacionais. Aproveitando desta conjuntura as organizações criminais vislumbram no comércio de seres humanos como um negócio lucrativo ${ }^{155}$.

Não obstante, as políticas migratórias dos países de destino tendem a priorizar a luta contra o tráfico irregular de pessoas/contrando (smuggling), caindo assim em uma crescente intolerância pelas migrações irregulares, sem guardar o devido respeito à proteção dos direitos humanos das vítimas de TP. Como afirma Gallanger, a conexão entre a TP e o Contrabando de imigrantes tem ocasionado dificuldade para animar aos governos a situar os direitos humanos no centro de seus debates políticos (GALLANGER, 2001, p. 26).

te", e que foram traficados outros 7 milhoes de escravos africanos, aproximadamente. Veja: DEL RÍO FERNÁNDEZ, L. J.: "Globalización e inmigración: El reto del siglo XXI", en La Ley, N 5 (2005), p. 1639. Durante este período da historia, o Europa foi predominantemente um continente de emigração, neste sentido veja: ROJO TORRECILLA, E.: "Inmigración y Derechos humanos: retos y perspectivas". In: Jueces para la democracia. No44 (junio 2002), p. 54. Sobre o impacto das migracoes na construcao da identidade com base na territorialidade veja: HAZEU, Marcel. Migração internacional de mulheres na periferia de Belém: identidades, famílias transnacionais e redes migratórias em uma cidade na Amazônia, 2011. Dissertação de Mestrado UFPA. Disponível em: http://repositorio.ufpa.br/jspui/ handle/2011/2987.

154 Para maiores informações veja: Informe sobre Derecho Comparado de la inmigración (Alemania, Francia, Italia, Reino Unido, Suecia y Unión Europea). Generalitat de Catalunya; marzo 2002, p. 9.

${ }^{155}$ De acordo com ONU se estima que move aproximadamente 9 bilhões de dólares por ano, sendo o terceiro delito internacional mais lucrativo. UNODC, 2010. Veja também: PÉREZ CEPEDA, A.I.:"Algunas consideraciones político-criminales previas a la incriminación del delito de tráfico de personas: Instrumentos internacionales en la lucha contra el tráfico de inmigrantes y la trata de seres humanos", en REDUR Nº (junio 2002), p. 45. 


\section{TRÁfico de PESSOAS: PRIMAZIA PELOS DIREITOS HUMANOS?}

O Protocolo de Palermo surge como uma necessidade de resposta em face aos novos desafios e metas que se apresentam no mundo globalizado. Com a adoção deste Protocolo, a Comunidade internacional se orienta de maneira que a violação aos Direitos humanos ocorridos no processo de TP seja reconhecida universalmente ${ }^{156}$. Ademais, vai mais além da compreensão tradicional de TP (para fins de prostituição forçada, conforme o Convênio de $1949^{157}$, referente ao objeto de proteção e, da dimensão punitiva), já que acrescenta uma compreensão multidimensional, aparte de adotar compromissos de prevenção ao delito de TP, proteção e assistência às vítimas e repressão dos traficantes ${ }^{158}$. Para Raymond, "instaura uma linguagem e uma legislação global para definir o tráfico de pessoas" (RAYMOND, 2001, p. 492). É considerado o principal instrumento jurídico a nível mundial para combater o $\mathrm{TP}^{159}$.

$\mathrm{Na}$ Comunidade internacional, se considera que o Protocolo de Palermo expressa uma opinião moderna e progressista moderada, apresentando a realidade um tanto escondida - do crime de TP. Nele se incluem todas as formas de movimento de pessoas, documentado e não documentado, através ou dentro das fronteiras, por qualquer meio em que o objetivo seja a exploração.

Aludido instrumento internacional de proteção delineia a extensão e a busca da defesa dos direitos humanos, ao combinar a proteção e assistência às vítimas, por meio da prevenção, punição, repressão e cooperação judicial com vistas a salvaguardar os direitos da pessoa. Para tais fins em seu artigo 3, encontramos a seguinte definição de TP:

a) A expressão "tráfico de pessoas" significa o recrutamento, o transporte, a transferência, o alojamento ou o acolhimento de pessoas, recorrendo à ameaça ou uso da força ou a outras formas de coação, ao rapto, à fraude, ao engano, ao abuso de autoridade ou à situação de vulnerabilidade ou à entrega ou aceitação de pagamentos ou benefícios para obter o consentimento de uma pessoa que tenha autoridade sobre outra para fins de ex-

\footnotetext{
${ }^{156}$ ONU, doc: A/CONF.213/, de 5 de fevereiro de 2010, párr. 54. $12^{\circ}$ Congreso de las Naciones Unidas sobre Prevención del Delito y Justicia Penal Salvador (Brasil), 12 a 19 de abril de 2010 .

${ }^{157}$ Convênio para a Repressão do Tráfico de Pessoas e da Exploração da Prostituição Alheia. Resolução 317(IV) da Assembleia Geral da ONU de 1949.

${ }^{158} \mathrm{O}$ que comumente é chamado o triplo 'P' do Protocolo de Palermo (Perseguição/Punição, Proteção e Prevenção).

${ }^{159}$ Conforme a Decisão 4/4 - La trata de seres humanos adotada no $4^{\circ}$ período de sessões, da Conferência das Partes da Convenção de Palermo: Reconheceu que o Protocolo Palermo é o principal instrumento juridicamente vinculante a nível mundial para combater o TSH. Em: CTOC/COP/WG.4/2010/2, p. 2.
} 
ploração. A exploração incluirá, no mínimo, a exploração da prostituição de outrem ou outras formas de exploração sexual, o trabalho ou serviços forçados, escravatura ou práticas similares à escravatura, a servidão ou a remoção de órgãos;

b) O consentimento dado pela vítima de tráfico de pessoas tendo em vista qualquer tipo de exploração descrito na alínea a) do presente Artigo será considerado irrelevante se tiver sido utilizado qualquer um dos meios referidos na alínea a);

c) O recrutamento, o transporte, a transferência, o alojamento ou o acolhimento de uma criança para fins de exploração serão considerados "tráfico de pessoas" mesmo que não envolvam nenhum dos meios referidos da alínea a) do presente Artigo;

De acordo com o exposto, a definição do TP contém três elementos: 1. Captação, transporte, traslado, acolhida ou recepção de pessoas; 2. Uso da ameaça; 3.Fins de exploração. Estes elementos estão inter-relacionados, já que se trata de uma ação que se assenta na captação, transporte, acolhida de pessoas, determinando assim uma conduta com o fim de exploração (CEPAL, 2003, p. 46). Para obter o consentimento de uma pessoa que tenha autoridade sobre outra se utiliza a ameaça, a força ou outras formas de coação, o rapto, a fraude e o engano, o abuso de poder diante uma situação de vulnerabilidade, assim como a concessão ou recepção de pagos ou benefícios; seu fim é a exploração ${ }^{160}$. Incluindo como mínimo a exploração da prostituição alheia ou outras formas de exploração sexual, trabalhos forçados, práticas análogas à escravidão, a remoção de órgãos ou tecidos, a mendicidade e exploração sexual infantil.

Já na opinião da Professora Leal (2002, p.44), a definição jurídica feita pelo Protocolo de Palermo confirma sua orientação limitada, já que se encontra caracterizado pelo uso da violência, pelo abuso da autoridade e pela coação. De este modo, para Leal não se permite uma descrição más detalhada das pressões estruturais e das estratégias de ação subjetivas inerentes ao fenômeno. Afirmando ainda que o mesmo: "É muito genérico, preso ao texto da violência criminal e fora de lugar de uma analise macro-social e cultural do fenômeno." Além de ser também uma definição ampla, que tampouco leva em consideração nem a idade nem o sexo. De acordo com seu posicionamento, para que ocorra um incremento na tipificação do $\mathrm{TP}$, seria necessário definir a exploração sexual comercial como:

\footnotetext{
${ }^{160}$ A este respeito Global Rights afirma: "A exploração como elemento central da expressão 'Tráfico de pessoas' não obteve uma definição legal, o que é criticado, com razão, porque deixa aos tribunais nacionais ampla margem de interpretação. Há que se considerar porém, que esta margem de interpretação não deve implicar abusos ou desvios quando aplicada por um judiciário funcional, num Estado de Direito. Ademais, os casos exemplificativos do Artigo $3^{\circ}$, alínea(a) limitam consideravelmente o espaço de discrição". Veja: GLOBAL RIGHTS. p. 8.
} 
“[...] uma violência sexual que se realiza nas relações de produção e mercado (consumo, oferta e excedente) através da venda dos serviços sexuais das crianças e adolescentes pelas redes de comercialização do sexo, por pais ou similares, ou por via do trabalho autônomo. Esta prática é determinada não apenas pela violência estrutural (plano de fundo), como pela violência social e interpessoal. É o resultado, também, das transformações ocorridas nos sistemas de valores arbitrados nas relações sociais, especialmente o patriarcalismo, o racismo, e a separação social, antíteses da idéia de emancipação das liberdades econômico/culturais e das sexualidades humanas." (LEAL, 2002, p. 44).

O Relatório Criminológico da Guarda Civil Espanhola de 2003/2004 aquece o debate sobre esta definição, já que manifesta que o fenômeno do TP é um tanto complexo por fazer referência a condutas criminais heterogêneas, que têm como objetivo comum a exploração de pessoas em suas distintas formas: já seja mediante a prostituição, a exploração laboral, a adoção ilegal, a venta de crianças, a pornografia infantil ou tráfico de órgãos, principalmente (ESPANA, 2005, p.3).

Em face do exposto, observamos que estamos diante uma definição sujeita a críticas; tanto pelo fato de conferir uma tipificação muito genérica para o TP, como "sujeita ao texto da violência criminal e fora de lugar em uma análise macro-social e cultural do fenômeno" (LEAL, 2002, p.44). Em consequência, coincidimos com Piscitelli de que o Protocolo sobre o TP deveria ter definido especificamente: a) Quais são as formas consideradas coercitivas; b) Que se considera uma "situação de vulnerabilidade"; c) A que se faz referencia com o termo "a exploração sexual de outros"; d) Que são "outras formas de exploração sexual" (PISCITELLI, 2004, p.7).

Não obstante, não se pode negar que pese a distintas críticas, o Protocolo de Palermo foi bem acolhido pela Comunidade internacional. Já que, por um lado, este normativo propiciou uma definição internacionalmente aceitada, fundamentada em três elementos constitutivos (ação, meio e fins) que facilitam a identificação de um caso de TP. Por outro, ha gerado o compromisso pelos Estados parte ao cumprimento das obrigações sobre a matéria de TP, baixo o triplo "P", da Proteção e assistência às vítimas, a Prevenção e combate ao crime, e a Punição e sanção dos delinquentes. Neste contexto, se pode vislumbrar o pano de fundo para a promoção dos Direitos humanos de uma parte através do controle judiciário da persecução e execução penal contra o traficante ou aliciador; e de outro, a proteção dos direitos humanos da vítima. Significando imprescindível uma ação conjugada do Estado com a sociedade civil, com vistas a redução dos fatores de risco, ao acolhimento e assistência integral das vítimas, e ações direcionadas de modo eficaz a prevenir e reprimir o TP .

Conscientes de que o TP é uma das formas más lucrativas do crime organizado transnacional (UNDOC, 2009), foi desenvolvido no seio da ONU o anteriormente mencionado Protocolo Relativo à Prevenção, Repressão e Punição do Tráfico 
de Pessoas, em Especial Mulheres e Crianças, como uma ferramenta de aplicação da norma internacional orientada para a proteção dos Direitos humanos das vítimas de $\mathrm{TP}^{161}$. Isso se produz para satisfazer o desejo dos Estados de criar um instrumento para combater o enorme crescimento do crime organizado transnacional, assim como a necessidade de conferir proteção às vítimas envolvidas em mencionado delito. De acordo com o Alto Comissionado de Direitos Humanos:

"[...] el enfoque basado en los derechos humanos es un enfoque basado desde el punto de vista normativo en las normas internacionales de derechos humanos y dirigido desde el punto de vista operacional a la promoción y la protección de los derechos humanos. Un enfoque de ese tipo requiere un análisis de las formas en que se vulneran los derechos humanos a lo largo de todo el ciclo de la trata de personas, así como de las obligaciones de los Estados en virtud del derecho internacional de los derechos humanos" $" 162$.

O enfoque nos Direitos humanos, como afirma o Alto Comissionado expressa que: "todos los aspectos de la respuesta nacional, regional e internacional a la trata de personas queda anclada en los derechos y las obligaciones establecidas por el derecho internacional de los derechos humanos" (OACDH, 2010, p. 51).

De acordo com o artigo 10 da Convenção de Palermo, os Estados Parte estão obrigados a adotar "as medidas que sejam necessárias", com o objetivo de: “estabelecer a responsabilidade de pessoas jurídicas ${ }^{163}$ pela participação em delitos

${ }^{161}$ A primazia dos direitos humanos das vitimas tem sido confirmada pela Comunidade internacional e por distintos órgãos de direitos humanos do sistema da ONU através de inúmeras resoluções, informes, recomendações. Entre elas: E/2002/68/Add.1, de 20 de mayo de 2002. Principios recomendados sobre los derechos humanos y la trata de personas. Informe del Alto Comisionado de las NU para lo DDHH al Consejo Económico y Social; Naciones Unidas, doc: A/RES/63/156, 30 de enero de 2009. Resoluciones de la Asamblea General 63/156: Trata de Mujeres y niñas; doc: A/RES/61/144, $1^{\circ}$ de febrero de 2007. Resolución de la Asamblea General 61/144: Trata de Mujeres y niños; doc: A/RES/59/166, 10 de febrero de 2005. Resolución 59/166: trata de mujeres y niños; resolución 11/3 del Consejo de Derechos Humanos sobre la trata de personas, especialmente mujeres y niños (17 junio 2009); El informe de la Relatora Especial sobre la trata de personas, especialmente mujer y niños, Sr Joy Ngozi Ezeilo, doc: A/HRC/10/16, 20 de febrero de 2009, párr. 44; Informe de la Relatora Especial sobre los derechos humanos de las víctimas de trata de personas, especialmente mujeres y niños, Sra. Sigma Huda (E/CN.4/2006/62, 13 a 27 de marzo de 2006), párr. 81, entre otros.

162 OACDH: Principios y directrices recomendados sobre derechos humanos y trata de personas (Comentario). HR/PUB/10/2. Nueva York y Ginebra: Naciones Unidas, 2010, pp. 5152. Assim mesmo destaca que: "Pretende identificar la forma de corregir las prácticas discriminatorias y la distribución injusta del poder que subyacen en la trata de personas, y que mantienen en la impunidad a los responsables y niegan justicia a las víctimas." Ibidem, p. 52. ${ }^{163} \mathrm{O}$ apartado 2) dispõe: "La responsabilidad de las personas jurídicas podrá ser de índole 
graves em que esteja envolvidos um grupo delitivo organizado". Este caráter obrigatório dos Estados é de grande relevância no terreno da luta contra a criminalidade relacionada ao TP, uma vez que, na medida em que se possibilita, por exemplo, o "confisco de bens"164, destinando parte do mesmo à criação de fundos para a indenização das vítimas, nos casos em que o TP seja realizado por pessoas que estejam envolvidas em redes criminais.

\section{Contrabando de imigrantes: INFRAÇÃo ADMinistrativa E ABUSO DA VUL- NERABILIDADE}

A Comunidade internacional se mostra atenta às tensões causadas nos processos migratórios irregulares e convicta da necessidade de tratar os migrantes com humanidade e proteger plenamente seus direitos ${ }^{165}$, e já cientes do o aumento significativo das atividades dos grupos criminosos organizados relacionadas com Contrabando de migrantes e outras atividades criminosas conexas ${ }^{166}$. Evidencia sua preocupação com fato de o tráfico irregular de migrantes muitas vez colocar em risco a própria vida dos migrantes. De resto a forma de migração irregular acarreta situação de vulnerabilidade para o imigrante que poderá se converter em uma vitima de TP. Cientes desta "tensão", foi também celebrado o Protocolo sobre o Tráfico irregular de imigrantes ${ }^{167}$ - que como já sinalamos optamos pelo termo Contrabando de imigrantes - cujo objetivo prevenir e combater o tráfico de migrantes (artigo 2) e se encontra definido no o artigo $3^{\circ}$ institui, entre outras, as definições a que se segue:

a) A expressão "tráfico de migrantes" significa a promoção, com o objetivo de obter, direta ou indiretamente, um benefício financeiro ou outro benefício material, da entrada ilegal de uma pessoa num Estado Parte do qual essa pessoa não seja nacional ou residente permanente;

b) A expressão "entrada ilegal" significa a passagem de fronteiras sem preencher os requisitos necessários para a entrada legal no Estado de acolhimento.

c) A expressão "documento de viagem ou de identidade fraudulento" sig-

penal, civil o administrativa." Asimismo corresponde a cada Estado: “4. (...) velará en particular por que se impongan sanciones penales o no penales eficaces, proporcionadas y disuasivas, incluidas sanciones monetarias, a las personas jurídicas consideradas responsables con arreglo al presente artículo."

${ }^{164}$ Conforme os artigos 5, 12, e 14 da Convenção de Palermo.

165 Protocolo sobre o Tráfico irregular de imigrantes, Preâmbulo: terceiro parágrafo.

${ }^{166}$ Ibidem, quinto parágrafo.

167 Anteriormente citado na nota 6: "Protocolo Adicional à Convenção das Nações Unidas contra o Crime Organizado Transnacional, relativo ao Combate ao Tráfico de Migrantes por Via Terrestre, Marítima e Aérea". 
nifica qualquer documento de viagem ou de identificação: (i) Que tenha sido falsificado ou alterado de forma substancial por uma pessoa ou uma entidade que não esteja legalmente autorizada a fazer ou emitir documentos de viagem ou de identidade em nome de um Estado; ou (ii) Que tenha sido emitido ou obtido de forma irregular, através de falsas; declarações, corrupção ou coação ou qualquer outro meio ilícito; ou (iii) Que seja utilizado por uma pessoa que não seja seu titular legítimo.

No contexto do contrabando de imigrantes percebemos que a criminalização deste satisfaz a uma lógica de proteção à rigidez dos limites de fronteira e de regularidade migratória (políticas migratórias restritivas), que propriamente à de refrear a exploração da pessoa do migrante, de regra também exposto a situação típica de vulnerabilidade. Para Cançado Trindade: The increasing controls and current hardships imposed upon migrants have led some to behold and characterize a contemporary situation of "crisis" of the right of asylum (TRINDADE, 2008, p.139). Nesta lógica, grupos criminosos propiciam - mediante altas quantias de capital - a possibilidade de migração aos que se encontram impedidos de realizar este anseio.

\section{Confusões conceituais entre o tráfico de pessoas e o contrabando ILEGAL DE IMIGRANTES}

Já apresentados os conceitos internacionalmente aceitados, neste ponto se faz necessário diferenciar entre TP e Contrabando de imigrantes, já que muitas vezes são utilizados como sinônimos pese referir-se a conceitos diferentes como expostos com anterioridade ${ }^{168}$. Objetivando brindar uma clareza conceitual destacamos as principais discrepâncias entre os dois conceitos, de conformidade com dois dos Protocolos que complementam a Convenção de Palermo.

A diferença entre os dois conceitos reside em que o contrabando de imigrantes consiste em facilitar o traslado, a travessia ou entrada irregular de uma pessoa a um país estrangeiro, mediante o pagamento de dinheiro ou outros benefícios; finalizando a relação entre o imigrante e o "coiote" (ou atravessador) com a chegada a seu destino. Tráfico é uma situação de abuso devido à dificuldade de imigrar pelas vias legais. Por isso que os "coiotes" "atravessadores" aproveitam para sacar partido

\footnotetext{
${ }_{168}$ Ainda que sejam conceitos diferenciados também possuem nexos de união que o desejo de melhores suas condições de vida que lhes empurra a um projeto migratório sem sopesar as conseqüências. Neste contexto também se faz importante tomar consciências dos fatores causantes neste projeto migratório, como salienta a Relatora especial sobre a violência contra a mulher destaca que o "la trata de personas debe de considerarse en el contexto de los movimienos y migraciones internacionales y nacionales que tienen cada vez mayor intensidad a causa de la mundialización econômica, la feminización de la migración, los conflictos armados, la desintegración o reconfiguración de los Estados y la transformación de las fornteras políticas.” Em: ONU, doc: E/CN.4/2000/68, parr. 1.
} 
explorando financeiramente aos migrantes que desejam sair de seu país. O traficante não oferece nenhuma garantia já que sua relação consiste na travessia de fronteiras; uma vez realizado o pagamento e a chegada ao país de destino, finaliza a relação (VAZ CABRAL, 2006, p.17). Portanto, a pessoa envolvida no contrabando de imigrantes, comete uma infração administrativa contra o Estado. Sem embargo, no TP pode ou não haver cruzamento de fronteiras (baixo engano, fraude ou coerção), com o fim de explorar o trabalho alheio. Consequentemente, se produz uma violação dos direitos humanos (ainda que a vítima haja dado seu consentimento inicial para a "viagem"), já que a vítima se encontra baixo situação de ameaça, coação e/ou violência entre outros direitos violados.

Tanto no contexto de TP como no de Contrabando de imigrantes, a definição dos conceptos foi uma conquista nos dois protocolos. Ainda que não estejamos diante definições perfeitas ${ }^{169}$, são ferramentas importantes para alcançar avances no sentido de respeito e proteção dos direitos humanos violados nos processos migratórios. $\mathrm{Na}$ Comunidade internacional, são parâmetros que ajudam ao entendimento tanto do contrabando de imigrantes, como do TP. Neste sentido, Gallanger (2001, p. 26) afirma que definir TP e diferenciá-lo do contrabando de imigrantes é um ponto de partida para combatê-los de maneira mais efetiva. Assim mesmo, sustenta que: "Incorporation of a common understanding of trafficking and migrant smuggling in to national laws and policies will enable states to cooperate and collaborate more effectively than ever before." (GALLANGER, 2001, pp. 26-27) ${ }^{170}$.

De uma forma muito simplificada, podemos observar no quadro a seguir os elementos que ajudam a estabelecer a diferença entre o TP e o Contrabando de imigrantes.

\footnotetext{
${ }_{169}$ Para mais consideraçoes sobre o impacto dos dois protocolos para o sistema de proteçao dos directos humanos, veja: GALLANGER, A.: Trafficking, Smuggling and Human Rights, op. cit. pp. 26-28. Para esta autora, o crecimento do TSH e do Contrabando de inmigrantes é uma consequência direta do fracasso mundial para gestionar a migraçao sem tratar suas causas profundas.

${ }^{170}$ A este respeito Vaz Cabral assevera: "La migration légale étant devenue presque impossible, una véritable marché s'est développé; le Prix de l'émigration est exorbitant. De plus, le trafic de migrants est, par définition, transnacional, alors que la traite peut être nationale." Veja: VAZ CABRAL, G. La traite des êtres humains, op. cit., p. 17.
} 


\begin{tabular}{|c|c|c|}
\hline & Tráfico de Seres Humanos (Trafficking) & $\begin{array}{l}\text { Contrabando de imi- } \\
\text { grantes }(\text { Smuggling })\end{array}$ \\
\hline Como começa? & $\begin{array}{l}\text { Geralmente o contato ocorre sob situações } \\
\text { de engano, e/ou abuso, e/ou coação. }\end{array}$ & $\begin{array}{l}\text { O migrante estabelece } \\
\text { contato direto e voluntario } \\
\text { com o traficante. }\end{array}$ \\
\hline Âmbito de atuação & $\begin{array}{l}\text { Pode ocorrer tanto nacional como interna- } \\
\text { cionalmente (Dentro ou fora do país). }\end{array}$ & $\begin{array}{l}\text { Implica sempre a travessia } \\
\text { de fronteiras. }\end{array}$ \\
\hline $\begin{array}{l}\text { Relevância do pagamen- } \\
\text { to para concretizar do } \\
\text { ato "delitivo }\end{array}$ & $\begin{array}{l}\text { O dinheiro para trasladar-se não é um fator } \\
\text { importante. }\end{array}$ & $\begin{array}{l}\text { O dinheiro é um fator in- } \\
\text { trínseco no traslado. }\end{array}$ \\
\hline Sujeitos envolvidos & $\begin{array}{l}\text { A relação entre tratante e vítima não finali- } \\
\text { za com o transpasso de fronteiras. }\end{array}$ & $\begin{array}{l}\text { A relação entre traficante e } \\
\text { migrante termina quando } \\
\text { chega ao destino. }\end{array}$ \\
\hline Tipo de vítimas & $\begin{array}{l}\text { Suas vítimas fundamentais são mulheres e } \\
\text { menores. }\end{array}$ & $\begin{array}{l}\text { Implica majoritariamente } \\
\text { homens. }\end{array}$ \\
\hline Riscos & $\begin{array}{l}\text { Se minimizam os riscos para a saúde e a } \\
\text { vida durante o traslado, mas a longo prazo } \\
\text { o impacto físico e psicológico é muito más } \\
\text { prolongado. }\end{array}$ & $\begin{array}{l}\text { Durante o traslado tem } \\
\text { maiores riscos para a saúde } \\
\text { e a vida do imigrante. }\end{array}$ \\
\hline $\begin{array}{l}\text { Contra quem se produz } \\
\text { o delito? }\end{array}$ & $\begin{array}{l}\text { É um delito contra o individuo (violação } \\
\text { sistemática de seus direitos humanos). }\end{array}$ & $\begin{array}{l}\text { É fundamentalmente uma } \\
\text { infração contra o Estado. }\end{array}$ \\
\hline
\end{tabular}

Estas diferenças apresentadas se fazem imprescindíveis para acionar a obrigação dos Estados de conferir proteção integral às vitimas de TP. Não obstante, não se pode tratar ao imigrante que usa das distintas vias irregulares de imigração como um criminal. E sim um ser humano que usando de liberdade de movimento, busca melhores condições de vida para realizar um trabalho digno e diante de política migratórias restritivas se vê obrigado a recorrer a meios irregulares propiciados pelas redes de contrabando de imigrantes.

\section{Conclusão}

Ao não brindar uma clareza conceitual se prioriza a luta contra imigração irregular, seja com políticas migratórias restritivas, seja confundindo as vitimas de TP como imigrantes, ou marginalizando aos imigrantes e colocando-os em situação de vulnerabilidade passiveis à exploração, não oferecendo a proteção devida.

O Conceito de TP deve sempre levar em consideração uma perspectiva multidisciplinar, dentre elas: a de gênero, a de direitos humanos, a demográfica, a econômica, a de saúde pública e de segurança pública (tendo em consideração também os aspectos de segurança humana) ${ }^{171}$. Evidenciando que no TP se deve levar em

${ }^{171}$ A este respeito, o Secretario General da ONU considera que: "El problema se ha abordado desde diversos puntos de vista, a saber, a) los derechos humanos, en particular como discriminación contra la mujer y violencia contra la mujer; b) la migración y su reglamentación; 
consideração que nos encontramos diante de um conceito síntese: já que trata-se de uma categoria que descreve a conjunção de diversos crimes, de modo praticamente simultâneo, em uma só pessoa quebrando com isso sua liberdade e dignidade.

Vale ressaltar que o TP está estreitamente unido com a escravidão, é uma violação de direitos humanos, uma violência de gênero, um crime contra a humanidade (conforme o art. 7 do Estatuto de Roma da Corte Penal Internacional), e que consiste em afastar uma pessoa de seu entorno ou origem com fim de explorá-la em outro lugar de destino ${ }^{172}$. A este respeito, a jurisprudência internacional ${ }^{173}$ interpretou que o Tráfico possui estreita relação com a escravidão, seja pelo domínio ou pela exploração do trabalho alheio.

Coexistem diferentes formas de TP, já que a exploração pode ser de caráter laboral - constrangendo a vítima a realizar trabalhos forçados, sem remuneração, e/ ou com isolamento, de servidão por dívidas (supostamente contraídas), ou sexual (para abastecer o mercado sexual); Do mesmo modo, pode ser para fins sexuais/comerciais, submetendo a vítima à prostituição ou à escravidão sexual ${ }^{174}$. $\mathrm{O}$ traficante se aproveita da situação de vulnerabilidade da pessoa, já que a mesma se encontra em um lugar alheio e estranho a seu entorno social.

O exposto até agora nos faz questionar sobre os avances sobre esta matéria para defesa dos Direitos humanos das vitimas de TP. Já que a Comunidade internacional se orgulha da luta que se leva a cabo contra o TP. Neste sentido, diante da confusão conceitual entre o TP e o Contrabando de imigrantes, nos questionamos se o que realmente importa é combater a lacra social que é o TP, ou realizar um controle de fronteiras e acabar com a delinquência organizada? Não negamos a necessidade de se enfrentar de modo ativo a delinqüência, seja ela nacional ou transnacional or-

c) la prevención del delito y d) los servicios sociales". Em: ONU: doc: A/50/369, párr. 45.

${ }^{172}$ Como assegura Vaz Cabral "La traite des femmes est généralement examinée sous l'angle de la criminalité. Il est rare que les femmes et les fillettes en question soient considérées comme les victimes d'un système inégalitaire en genre, alors que les violations des droits humains qu'elles subissent sont à la fois une cause et une conséquence de la traite. C'est pourquoi la question de la traite des femmes ne peut être abordée sans une analyse de genre qui permettra notamment de comprendre pourquoi la migration peut être perçue par certaines femmes comme le seul moyen d'échapper à leur détresse, quelle place leur est donnée dans la société et quelle autre stratégie de lutte s'offre à elles pour améliorer leur condition ». Veja: VAZ CABRAL, G.: La Traite des êtres humains. Réalités de l'esclavage contemporain. La découverte. Paris, 2006, p. 7.

173 TPIY 2001 Case Prossecutor v. KUNARAC e outros e no TEDH : Caso Rantsev v. Rússia e Chipre em 2010.

${ }^{174}$ Ante mencionada perspectiva Kara explica cómo se desarrolla el negocio de la esclavitud sexual: "La adquisición de esclavas sexuales se produce principalmente mediante uno de estos cincos medios: el engaño, la venta por la familia, el rapto, la seducción e el cortejo o la captación con la ayuda de otras esclavas." Véase: KARA, S.: Tráfico Sexual. El negocio de la esclavitud moderna. Madrid: Alianza editorial, 2010, p.30. 
ganizada, ou mesmo as "redes familiares" que sustentam o TP. Sem embargo, não se pode obviar que nos dois processos analisados fazermos referência ao movimento de seres humanos, no qual se deve prevalecer como eixo motor a liberdade e dignidade humana.

\section{REFERÊNCIAS}

CALVANI, S. Representante do UNODC, Bogotá-Colômbia, Convenção de Palermo. Disponível em: http://www.sandrocalvani.com/speech/Conv.\%20Palermo.pdf.

CANÇADO TRINDADE, Antônio Augusto. Uprootedness and the protection of migrants in the International Law of Human Rights. Revista Brasileira de Política Internacional [en línea] 2008, vol. 51 [citado 2012-08-30]. Disponível em: http:// redalyc.uaemex.mx/src/inicio/ArtPdfRed.jsp?iCve=35811693008.

CEPEDA, Ana Isabel Peréz. Globalización, Tráfico Internacional ilícito de personas y derecho penal. Granada: Comares, 2004.

CHIAROTTI, Susana. Trata de Mujeres: Conexiones y Desconexiones entre Género, Migración y Derechos Humanos. Conferencia Hemisférica sobre Migración Internacional: Derechos Humanos y Trata de Personas en las Américas. CEPAL, Santiago de Chile, 20 a 22 de noviembre de 2002.

CORRÊA DA SILVA, W. Tráfico de Pessoas: Cenário, Atores e Crime. Em busca do Respeito à Dignidade Humana. Ed. UFMt: Rio de Janeiro, 2011.

CUNHA, Guilherme L. da. Migraçoes, Direitos Humanos e Direito de Asilo. In: BAPTISTA, Luiz Olavo; FONSECA, José Roberto Franco da. O direito internacional no terceiro milênio. São Paulo: Ltr, 1998.

DEL RÍO FERNÁNDEZ, L. J.: “Globalización e inmigración: El reto del siglo XXI’. La Ley, No5, 2005.

ESPAÑA. Informe crimonologico tráfico de seres humanos con fines de explotación sexual (2003/2004) Guardia Civil - Unidad Técnica de Policía Judicial.

HAZEU, Marcel. Migração internacional de mulheres na periferia de Belém: identidades, famílias transnacionais e redes migratórias em uma cidade na Amazônia. UFPA, Belém, 2011. Dissertação de Mestrado UFPA. Disponível em: http://repositorio.ufpa.br/jspui/handle/2011/2987.

HELD, David: MACGREW, Anthony; GOLDBLATT, David. Global Transformations. California: Stanford University, 1999.

GALLANGER, A. Trafficking, Smuggling and Human Rights: Trick and treaties". Forced Migration Review, December, 2001.

IIDH/Instituto Interamericano de Derechos Humanos. Migración y derechos huma- 
nos: Reunión de personas expertas. San José, C.R.: Instituto Interamericano de Derechos. Humanos, 2004.

KARA, S. Tráfico Sexual. El negocio de la esclavitud moderna. Madrid: Alianza editorial, 2010.

ONU, doc: A/CONF.213/, de 5 de fevereiro de 2010, párr. 54. $12^{\circ}$ Congreso de las Naciones Unidas sobre Prevención del Delito y Justicia Penal Salvador (Brasil), 12 a 19 de abril de 2010.

ONU, doc: E/CN.4/2000/68, de 29 de fevereiro de 2000. Informe de la Relatora especial de violência contra la mujer: sus causas y conseqüências.

OACDH: Principios y directrices recomendados sobre derechos humanos y trata de personas (Comentario). HR/PUB/10/2. Nueva York y Ginebra: Naciones Unidas, 2010 .

PÉREZ CEPEDA, A.I. Algunas consideraciones político-criminales previas a la incriminación del delito de tráfico de personas: Instrumentos internacionales en la lucha contra el tráfico de inmigrantes y la trata de seres humanos. REDUR, Junio 2002.

PISCITELLI, A.: Entre a praia de Iracema e a União Européia: turismo sexual internacional e migração feminina. Em: PISTICELLI, A. et alli (org) Sexualidade e saberes: convenções e fronteiras. Rio de Janeiro, Garamond, 2004.

RAYMOND, J. G. “The New UN Trafficking Protocol.” Women's Studies International Forum. Vol. 25, n.5 2002.

UNODOC. Manual para la lucha contra la trata de personas. New York: UNODC, 2009.

UNODOC. Trata de Personas hacia Europa con fines de explotación sexual. UNDOC. Ginebra/NY, 2010.

VAZ CABRAL, G. La traite des êtres humains: Realités de l'esclavage contemporain. La Découverte. Paris, 2006. 